\title{
Heliospheric magnetic field 1835-2009
}

\author{
Leif Svalgaard $^{1}$ and Edward W. Cliver ${ }^{2}$ \\ Received 3 November 2009; revised 24 March 2010; accepted 12 May 2010; published 24 September 2010.
}

[1] We use recently acquired geomagnetic archival data to extend our long-term reconstruction of the heliospheric magnetic field (HMF) strength. The 1835-2009 HMF series is based on an updated and substantiated InterDiurnal Variability (IDV) series from 1872 onwards and on Bartels' extension, by proxy, of his $u$-series from 1835 to 1871 . The new IDV series, termed IDV09, has excellent agreement $\left(\mathrm{R}^{2}=0.98 ; \mathrm{RMS}=0.3 \mathrm{nT}\right)$ with the earlier IDV05 series, and also with the negative component of Love's extended (to 1905) $D_{s t}$ series $\left(\mathrm{R}^{2}=0.91\right)$. Of greatest importance to the community, in an area of research that has been contentious, comparison of the extended HMF series with other recent reconstructions of solar wind $B$ for the last $\sim 100$ years yields a strong consensus between series based on geomagnetic data. Differences exist from $\sim 1900-1910$ but they are far smaller than the previous disagreement for this key interval of low solar wind $B$ values which closely resembles current solar activity. Equally encouraging, a discrepancy with an HMF reconstruction based on ${ }^{10} \mathrm{Be}$ data for the first half of the 20th century has largely been removed by a revised ${ }^{10} \mathrm{Be}$-based reconstruction published after we submitted this paper, although a remaining discrepancy for the years $\sim 1885-1905$ will need to be resolved.

Citation: Svalgaard, L., and E. W. Cliver (2010), Heliospheric magnetic field 1835-2009, J. Geophys. Res., 115, A09111, doi:10.1029/2009JA015069.

\section{Introduction}

[2] Svalgaard and Cliver [2005] introduced the InterDiurnal Variability (IDV) index for a given geomagnetic observatory ("station") as the average difference without regard to sign, from one day to the next, between hourly mean values of the Horizontal Component, $H$, and measured one hour after midnight. The average should be taken over a suitably long interval of time, such as one year, to eliminate various seasonal complications.

[3] IDV has the useful property of being independent of solar wind speed and is highly correlated with the nearEarth heliospheric magnetic field (HMF) strength $B$. Thus once $I D V$ is determined, solar wind $B$ is known as well. Svalgaard and Cliver [2005] used IDV augmented with Bartels' [1932] $u$-measure to reconstruct the HMF strength for the years 1872-2004.

[4] Here we report on an extension of the $I D V$ index for a longer time interval (1835-2009), using many more stations. The inclusion of more data is particularly important for the years from 1890 to 1909 for which the initial version of the index (IDV05) was based on observations from only one station before 1901 and four more stations from 1903. An important aspect of IDV09 is that it includes recent years

\footnotetext{
${ }^{1}$ HEPL, Stanford University, Stanford, California, USA.

${ }^{2}$ Space Vehicles Directorate, Air Force Research Laboratory, Hanscom AFB, Massachusetts, USA.

Copyright 2010 by the American Geophysical Union. 0148-0227/10/2009JA015069
}

with index values at the same level as the very low values in 1901-1902, thus allowing the correlation between IDV and the magnitude of the near Earth HMF to be extended to such low values without extrapolation. With this correlation, we infer HMF $B$ for years prior to the space age and compare our $B$ values with those obtained by other investigators using geomagnetic or cosmic ray data.

\section{Analysis}

\subsection{Derivation of IDV09}

[5] Our determination of IDV09 is essentially identical to that of IDV05 except for the inclusion of more data. Svalgaard and Cliver [2005] emphasized that IDV is a modern version of the $u$-measure building on ideas of a century ago [Moos, 1910]. Kertz [1958], Mayaud [1980], and Svalgaard [2005] suggested using only nighttime values to avoid contamination by the regular diurnal variation, $S_{R}$. We followed their lead but further limited the time interval to only one hour following local midnight and constructed the $I D V$ for a given station as the unsigned difference between two consecutive days of the average value over the interval of a $H$ component measured in $\mathrm{nT}$. The individual unsigned differences were then averaged over longer intervals, e.g., one full year (minimizing various geometric and seasonal effects, e.g., the semiannual non solar variation due to the tilt of the Earth's dipole - a plot of 27-day Bartels Rotation values of IDV is given by Svalgaard [2009]).

[6] Since 2005, we have been collecting, digitizing, quality controlling, and correcting (where needed) hourly 
Table 1. (continued)

Table 1. Stations Used for IDV09, Including Replacement Stations due to Relocation of Original Stations ${ }^{\mathrm{a}}$

\begin{tabular}{|c|c|c|c|c|}
\hline Stations & $\begin{array}{l}\text { Geodetic } \\
\text { Latitude }\end{array}$ & $\begin{array}{l}\text { Geodetic } \\
\text { Longitude }\end{array}$ & $\begin{array}{c}\text { Corrected } \\
\text { Geomagnetic } \\
\text { Latitude } 2000\end{array}$ & Divisor \\
\hline BOX & 58.0 & 39.0 & 53.9 & 1.10 \\
\hline $\mathrm{ESK}^{\mathrm{b}}$ & 55.3 & 356.8 & 52.9 & 1.00 \\
\hline EKT, SVD, ARS & 56.4 & 58.6 & 52.1 & 1.10 \\
\hline RSV, BFE & 55.6 & 11.7 & 52.1 & 1.10 \\
\hline MOS & 55.5 & 37.3 & 51.3 & 1.10 \\
\hline NVS & 55.0 & 82.9 & 50.5 & 0.97 \\
\hline WLH,WNG & 53.7 & 9.1 & 50.1 & 0.97 \\
\hline MNK & 54.1 & 26.5 & 49.9 & 0.98 \\
\hline CLH, FRD & 38.2 & 282.6 & 49.7 & 0.97 \\
\hline $\mathrm{BOU}$ & 40.1 & 254.8 & 49.2 & 0.99 \\
\hline BAL & 38.8 & 264.8 & 49.0 & 0.99 \\
\hline DBN, WIT & 52.1 & 5.2 & 48.4 & 0.98 \\
\hline $10 \mathrm{u}$ & 52.4 & 13.1 & 48.3 & 1.00 \\
\hline POT, SED, NGK & 52.1 & 12.7 & 48.0 & 1.00 \\
\hline ABN, HAD & 51.0 & 355.5 & 47.8 & 0.99 \\
\hline BEL & 51.8 & 20.8 & 47.5 & 1.01 \\
\hline IRT & 52.2 & 104.5 & 47.0 & 1.02 \\
\hline TKT & 41.3 & 69.6 & 46.5 & 1.08 \\
\hline PET & 53.1 & 158.6 & 46.3 & 1.02 \\
\hline DOU & 50.1 & 4.6 & 46.0 & 1.02 \\
\hline LVV & 49.9 & 23.8 & 45.3 & 1.04 \\
\hline PSM, VLJ, CLF & 48.0 & 2.3 & 43.6 & 1.04 \\
\hline FUR & 48.2 & 11.3 & 43.4 & 1.05 \\
\hline HRB & 47.9 & 18.2 & 43.0 & 1.06 \\
\hline THY & 46.9 & 17.9 & 41.8 & 1.08 \\
\hline YSS & 47.0 & 142.7 & 39.9 & 1.10 \\
\hline TUC & 32.3 & 249.2 & 39.9 & 1.10 \\
\hline AAA & 43.3 & 76.9 & 38.4 & 1.12 \\
\hline TFS & 42.1 & 44.7 & 37.2 & 1.14 \\
\hline MMB & 43.9 & 144.2 & 36.7 & 1.13 \\
\hline AQU & 42.4 & 13.3 & 36.3 & 1.13 \\
\hline BJI, BMT & 40.3 & 116.2 & 34.2 & 1.16 \\
\hline SFS, EBR & 40.8 & 0.5 & 34.2 & 1.14 \\
\hline COI & 40.2 & 351.6 & 34.1 & 1.15 \\
\hline LNP, LZH & 36.1 & 103.9 & 30.1 & 1.20 \\
\hline VQS, SJG & 18.4 & 293.9 & 29.2 & 1.20 \\
\hline KAK & 36.2 & 140.2 & 28.9 & 1.20 \\
\hline KNZ & 35.3 & 140.0 & 27.9 & 1.21 \\
\hline HTY & 33.1 & 139.8 & 25.7 & 1.23 \\
\hline SSH & 31.1 & 121.2 & 24.4 & 1.24 \\
\hline KNY & 31.4 & 130.9 & 24.3 & 1.24 \\
\hline $\mathrm{HON}$ & 21.3 & 202.0 & 21.7 & 1.26 \\
\hline GUI & 28.3 & 343.6 & 15.7 & 1.29 \\
\hline PHU & 21.0 & 106.0 & 13.7 & 1.30 \\
\hline ABG & 18.6 & 72.9 & 11.8 & 1.31 \\
\hline KOU & 5.1 & 307.4 & 10.8 & 1.30 \\
\hline MBO & 14.4 & 343.0 & 3.2 & 1.31 \\
\hline ANN & 11.4 & 79.7 & 3.1 & 1.32 \\
\hline TAM & 22.8 & 5.5 & 3.1 & 1.32 \\
\hline HUA & -12.1 & 284.7 & 2.1 & 1.32 \\
\hline GUA & 13.6 & 144.9 & 1.0 & 1.32 \\
\hline TRD & 8.5 & 77.0 & 0.4 & 1.32 \\
\hline AAE & 9.0 & 38.8 & -1.3 & 1.32 \\
\hline $\mathrm{BNG}$ & 4.4 & 18.6 & -2.2 & 1.32 \\
\hline ASC & -7.5 & 345.6 & -7.9 & 1.32 \\
\hline BTV & -6.2 & 106.8 & -15.8 & 1.29 \\
\hline PPT & -17.6 & 210.4 & -16.4 & 1.29 \\
\hline VSS & -22.4 & 316.4 & -16.5 & 1.30 \\
\hline PIL & -31.7 & 296.1 & -18.6 & 1.28 \\
\hline API & -138.8 & 188.2 & -24.6 & 1.25 \\
\hline TAN & -18.9 & 47.6 & -29.1 & 1.20 \\
\hline TSU & -19.2 & 17.7 & -30.0 & 1.20 \\
\hline HBK & -22.9 & 27.7 & -33.6 & 1.17 \\
\hline CTO, HER & -34.4 & 19.2 & -42.3 & 1.09 \\
\hline WAT, GNA & -31.8 & 116.0 & -44.4 & 1.05 \\
\hline TOO, CNB & -35.3 & 149.4 & -45.8 & 1.04 \\
\hline TRW & -43.3 & 19.0 & -47.8 & 1.02 \\
\hline
\end{tabular}

\begin{tabular}{lcccc}
\hline \multicolumn{1}{c}{ Stations } & $\begin{array}{c}\text { Geodetic } \\
\text { Latitude }\end{array}$ & $\begin{array}{c}\text { Geodetic } \\
\text { Longitude }\end{array}$ & $\begin{array}{c}\text { Corrected } \\
\text { Geomagnetic } \\
\text { Latitude 2000 }\end{array}$ & Divisor \\
\hline AMS $^{\mathrm{b}}$ & -37.8 & 77.6 & -49.1 & 1.00 \\
AIA & -65.2 & 295.7 & -49.8 & 1.20 \\
AML, EYR & -43.4 & 172.4 & -50.3 & 0.97 \\
CZT & -46.4 & 51.9 & -53.1 & 1.10 \\
\hline
\end{tabular}

${ }^{\mathrm{a}}$ The Corrected Geomagnetic Latitude for the year 2000 is given for illustration, but the centroid of the latitudes for the time of operation was used to estimate the Normalization Constants. Constants in italics were determined by an empirical fit to time-overlapping stations. Stations are given by the IAGA abbreviation. A list of IAGA designations, observatory names, and other station details can be found at http://www. geomag.bgs.ac.uk/gifs/annual_means.shtml.

${ }^{\mathrm{b}}$ Weakly nonlinear relationships have been used to normalize directly to NGK.

historical geomagnetic data from individual observatories as well as from World Data Centers (there is, as yet, no mechanism available to individual researchers for injecting new or corrected data into the World Data Centers or into various National Depositories, so we offer the data to interested researchers upon request). Here we use these newly acquired data to substantiate the $I D V$-index, which is especially important for the first $\sim 30$ years of the time series (1872-1902), during which IDV05 was based solely on Schmidt's [1926] and Bartels' [1932] $u$-measure from 1872 to 1889 , on Potsdam observations from 1890 to 1902 , plus Cheltenham for 1901-1902, and Honolulu for 1902. In contrast, IDV09 is based on four times as many "station years" (143 versus 34) for this 31-yr interval as detailed in Data Set S1 of the auxiliary material. ${ }^{1}$ We update the time series by adding the index values for 2004-2009. These latter years are significant because the yearly averages of $B$ observed in 2007-2009 are the lowest observed during the space age. They lie at the lower endpoint of the correlation between yearly averages of observed $B$ and $I D V$.

[7] Table 1 contains a list of the 71 stations (including replacement stations) used to compute IDV09 (versus 14 for IDV05). A comprehensive list of the data coverage and the data values for the individual stations used in this study is given in Data Set S1 in the auxiliary material. All raw data is available from the authors (LS) upon request.

\subsubsection{Latitude Normalization}

[8] For IDV05, we normalized $I D V$ values for a given station with Corrected Geomagnetic Latitude, $M$, to those of Niemegk (NGK; as Bartels did for the $u$-measure) using

$$
I D V_{\text {norm }}=I D V_{\text {raw }} /\left(1.324 \cos ^{0.7}(M)\right)
$$

[9] Here we have retained this relationship for stations with $|M|<51^{\circ}$ because it still fits the data for the additional stations. At significantly higher latitudes, the index becomes strongly contaminated by auroral zone activity [see Svalgaard and Cliver, 2005, Figure 2], and we recommended not using such stations, e.g., the long-running station Sodankylä, SOD (used by Lockwood et al. [2009]). For

\footnotetext{
${ }^{1}$ Auxiliary materials are available at ftp://ftp.agu.org/apend/ja/ 2009ja015069.
} 


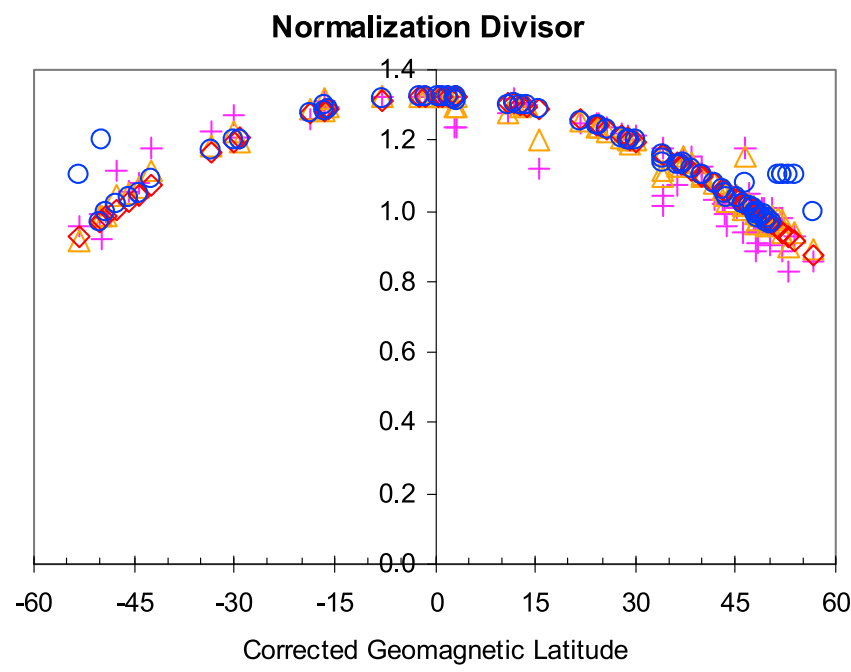

Figure 1. Adopted divisors (blue circles) to normalize $I D V$ to the NGK-scale as a function of average corrected geomagnetic latitude for each station over the time of operation. For each station, different color-coded symbols show what the divisor would have been for that station for years 1800 (pink pluses), 1900 (orange triangles), and 2000 (red diamonds).

IDV09, we relax this restriction slightly (by a few degrees for a few stations, indicated in Table 1 using a constant, empirical normalization divisor of 1.1 for these stations, instead of the divisor in equation (1)). A value larger than $\sim 0.95$ for $|M| \geq 51^{\circ}$ indicates some contamination by auroral zone activity. We have not attempted to further quantify the latitude dependence of the contamination, but simply use an average value for the few stations slightly above $51^{\circ}$. We do this to accommodate changes in $M$ with time which for some stations can exceed several degrees and to include a few long-running stations just above $51^{\circ}$. (We expect only a very weak influence in the basic response of the Ring Current (see section 2.1.5) to the change of the Earth's magnetic dipole moment (as per Glassmeier et al. [2004]) over the interval in question, and so have not attempted to correct for this.) Figure 1 shows the adopted normalization divisor as a function of $M$ for the 71 stations used in the present study. Different symbols denote the divisor values for the years 1800,1900 , and 2000, showing the sensitivity of $I D V$ to changes in latitude. The normalization divisor was calculated for the centroid of the latitudes for the actual data coverage for each station. If we did not normalize, the presence of data gaps (of which there are many) would produce discontinuities in the composite series.

\subsubsection{Effect of Hourly Means Versus Hourly Values on IDV}

[10] Early magnetometer data were taken (and/or reported) as readings once an hour rather than as the hourly mean that Adolf Schmidt advocated in 1905 and that was widely and rapidly adopted. Svalgaard and Cliver [2005] showed that although the variance of single values is larger than for averages, the overall effect on $I D V$ was small (at most a few percent). (This effect is significant for the
$I H V$ index, but for that case, correction of the effect is straightforward [Svalgaard and Cliver, 2007b].) The two long-running series POT-SED-NGK and PSM-VLJ-CLF afford a convenient additional test of this: POT changed from values to means with the 1905 yearbook, but CLF changed much later, with the 1972 yearbook, so we can directly compare the (raw - uncorrected in any way) $I D V$ values for the two series (Figure 2). It is evident that the change from hourly instantaneous values to hourly means did not introduce any sudden changes in $I D V$ at the times of the transitions. The Japanese station at KAK changed from values to means in 1955 . The ratio between raw $I D V$ for KAK and SED-NGK (crosses on Figure 2) also does not show any change in 1955. The American stations CLH and HON changed to means with the 1915 yearbook. Comparison (Figure 3) over a 24-year interval centered on 1915 with the stations VLJ and DBN, which did not change sampling procedure, also shows no detectable change in $I D V$ due to the change in sampling: the ratio between average CLH-HON and VLJ-DBN is 1.0792 before 1915 and 1.0792 after the change to hourly means in 1915 . We conclude that changes are too small to justify attempting ad hoc correction based on extrapolation of modern data.

\subsubsection{Using the $\boldsymbol{u}$-Measure Before 1872}

[11] Bartels [1932; Joos et al., 1952] compiled the $u$ measure from the interdiurnal variability of the Horizontal Component, $H$, from hourly or daily values from several observatories operating from 1872 onwards as described in his paper. He wrote, "Before 1872, no satisfactory data for the calculation of interdiurnal variabilities are available," but "more for illustration than for actual use," he attempted to extend the series backward to 1835 . For this he used the "Einheitliche Deklinations-Variationen" (Unified Declination Variations), E, of Wolf [1884] and the "summed ranges," $s$, derived from the mean diurnal variation of $H$ at Colaba (Bombay) due to Moos [1910]. He derived regression formulae relating $E$ and $s$ to $u$ for times after 1872 and used them to synthesize values of $u$ for the earlier years; giving $s$ double the weight of $E$. Bartels justified this by showing that for the annual means 1872-1901, the values of $u$ derived from $H$ and the values of $s$ have a high linear correlation coefficient. (From $E$ and $s$, we calculate a value of 0.72 for the value for $u$ for 1857.5 using the formulae given by Bartels.) We have extended his analysis by calculating the correlation between IDV and the Summed Ranges for 1872-1905 finding a correlation coefficient of 0.86 . Figure 4 shows the agreement between observed $I D V$ (red) and that calculated from $s$ (blue).

[12] Furthermore, as shown by Svalgaard and Cliver [2005] there is a good linear correlation between $I D V$ (or HMF $B$ derived from it) and the square root of the sunspot number, $R$. The main sources of the equatorial components of the Sun's large-scale magnetic field are large active regions. If these active regions emerge at random longitudes, their net equatorial dipole moment will scale as the square root of their number. Thus their contribution to the average HMF strength will tend to increase as $R^{1 / 2}$ (for a detailed discussion, see Wang and Sheeley [2003] and Wang et al. [2005]).

[13] To the extent that the $u$-measure before 1872 can be taken as a geomagnetic-based measure of the sunspot number, it is therefore to be expected that the $u$-measure 


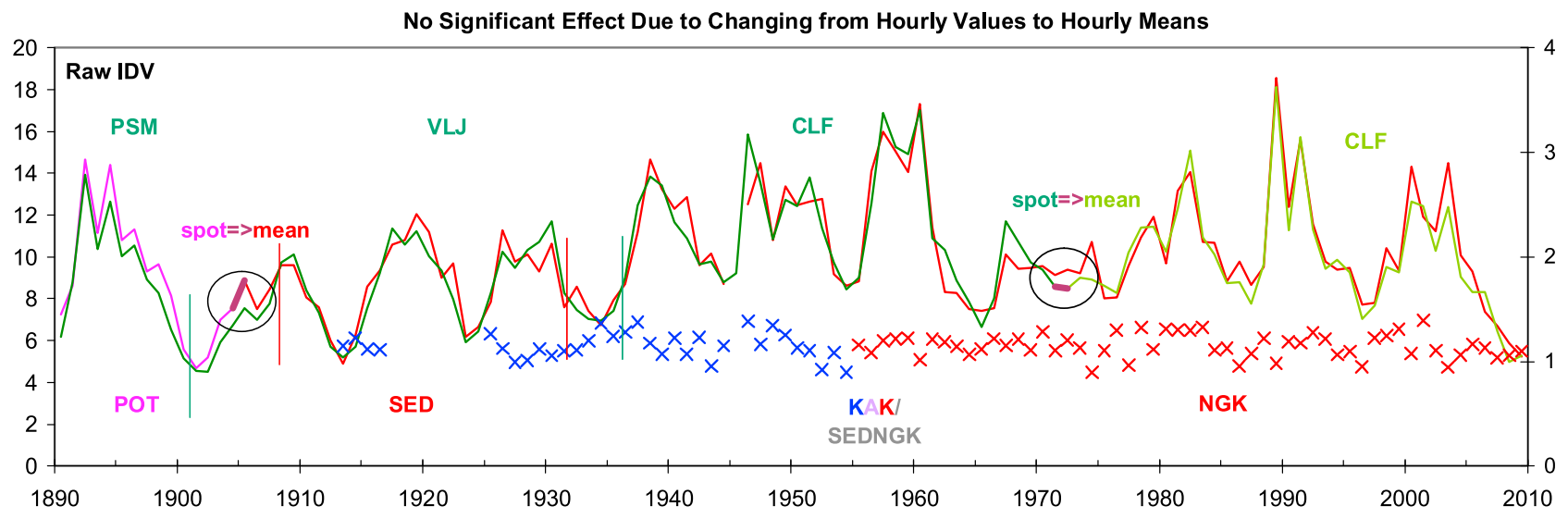

Figure 2. IDV calculated without any normalization or adjustments for the long-running German series (Potsdam POT-Seddin SED-Niemegk NGK; red curves) and the long-running French series (Parc SaintMaur PSM-Val Joyeux VLJ-Chambon-la-Forêt CLF; green curves). Vertical lines show when the replacement stations went into operation and the ovals show when the yearbook values changed from being instantaneous hourly spot values to hourly means. The blue (spot values) and red (hourly means) crosses show the ratio between raw $I D V \mathrm{~S}$ for KAK-Kakioka and SED-NGK. KAK changed from recording spot values to recording hourly means in 1955 . There are no clear indications of changes in $I D V$ due to the change in recording/reporting practice.

also will serve as a proxy for $I D V$. This estimate will be independent of any assumptions about the constancy of the calibration of the sunspot number (compare the difference between the Zürich Sunspot Number and the Group Sunspot Number [Hoyt et al., 1994]).

[14] Figure 5 shows that $I D V$ can also be directly inferred from the daily range, $r Y$, of the east component (equivalent to the Declination for this purpose) of the geomagnetic field and that therefore, again, that the $u$-index before 1872 (strongly influenced by the range of the daily variation) can be used for estimation of $I D V$, albeit with slightly less accuracy than after 1872. This conclusion may seem at variance (and did surprise us) with our initial decision to use only nighttime data in the derivation of $I D V$, but emerges naturally (and inescapably) after our analysis had shown that $I D V$ derived without any dependence on daytime data is comparable to $I D V$ derived from daily ranges because of the strong dependence of both on the sunspot number. This is clearly demonstrated in Figure 6 that shows raw IDV calculated for PSM-VLJ-CLF and POT-SED-NGK determined from nighttime differences (blue) and daytime differences (red). This realization opens the door for use of 19 th geomagnetic stations that only observed during the day as long as the observations were made at fixed hours.

[15] For the reasons given above, we find that $I D V$ can be estimated with confidence from Bartels' $u$-measure also before 1872, justifying our reconstruction of HMF $B$ since

\section{No Difference Between Spot and Mean Values Before and After 1915}

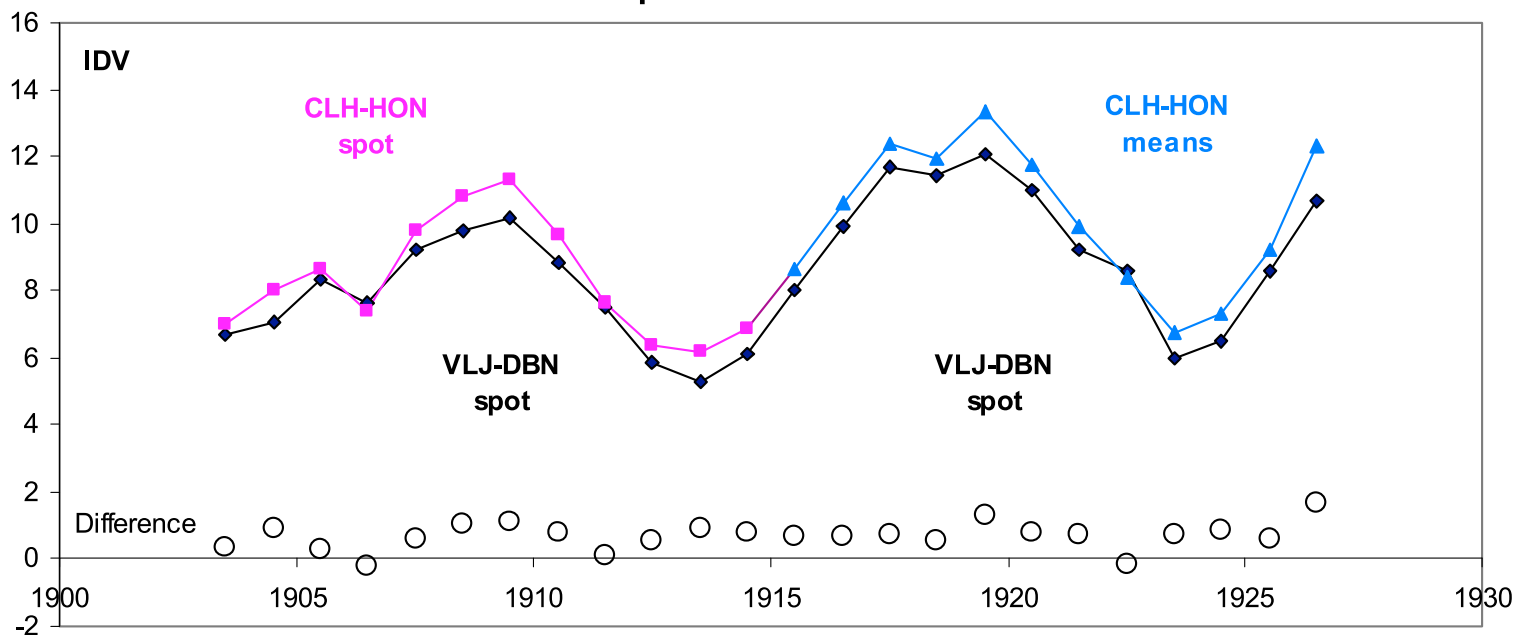

Figure 3. Raw $I D V$ for the average of stations VLJ and DBN (both reporting instantaneous "spot" values every hour for the 12-year intervals before 1915 and after 1915) and for the average of CLH and HON (reporting spot values before 1915 (pink) and hourly mean value thereafter (blue)). 


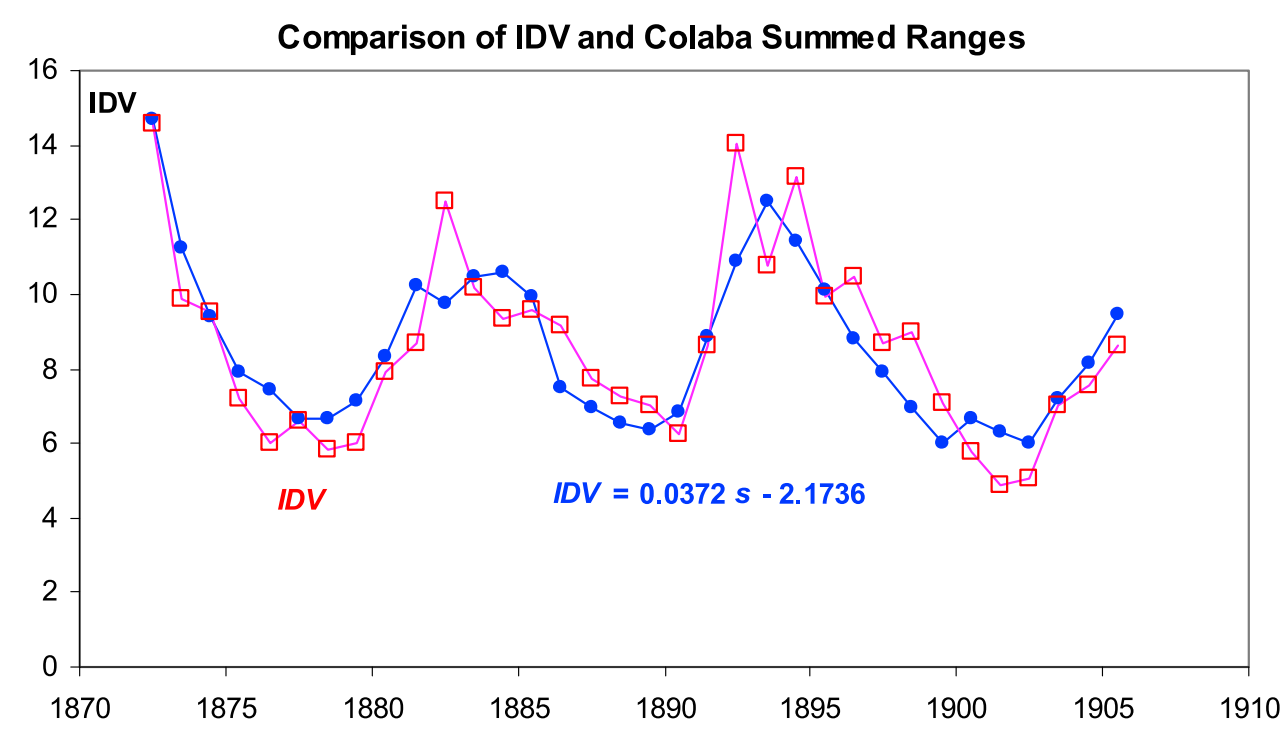

Figure 4. Comparison of observed $I D V$ (red open squares) and synthetic $I D V$ calculated from $s$ using the regression equation shown (solid blue circles) derived from the correlation between $I D V$ and the Summed Ranges, $s$, of $H$ from Colaba [Moos, 1910; p. 294, Table 261] for 1872-1905.

1835, with expected refinement of the reconstruction upon further digitization of 19th century geomagnetic yearbooks.

\subsubsection{IDV-Index 1835-2009}

[16] From the $\sim 1,375,000$ daily differences (3775 stationyears) derived from the stations in Table 1 we construct the $I D V$-index shown in Figure 7, with individual station curves in gray. The composite (red) curve is the mean of the median and average values for each year, while before 1872 the dashed curve shows $I D V$ estimated from $u$. Also shown (blue curve) is the number of stations contributing to the mean. The large number of stations from 1957 on does not add further significance to the composite, but only serves to establish the range of scatter of the values.

[17] It is evident that $I D V$ from only a single station (provided that not too much data is missing either because the recording went off-scale or as a result of other problems) does not differ much from the mean of many stations; the standard deviation of $I D V$-values for all stations for a given year is less than $1 \mathrm{nT}$ or about $9 \%$. This means that only a few (good) stations are needed for a robust determination of $I D V$. This conclusion, of course, only emerges after the spread of $I D V$-values has first been shown to be small. The

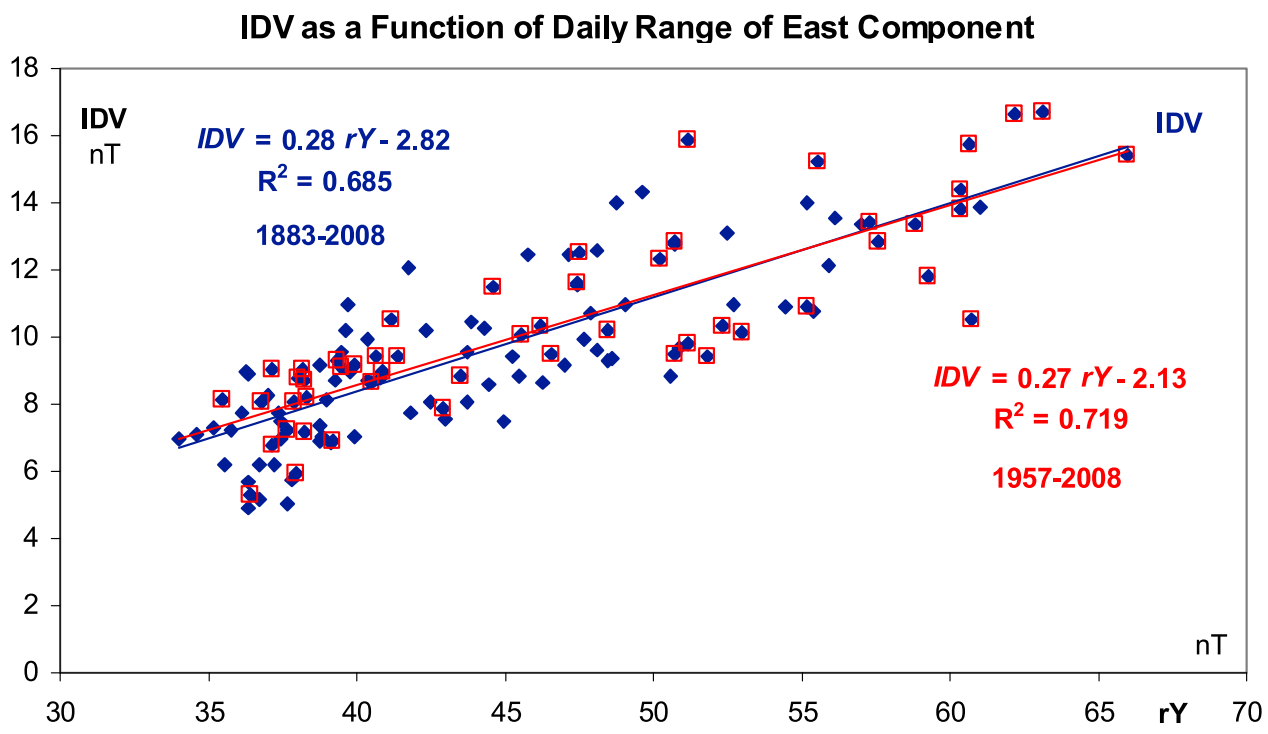

Figure 5. IDV plotted against the amplitude of the daily range, $r Y$, of the east component (Data Set $\mathrm{S} 2$ in the auxiliary material) of the geomagnetic field derived from PSM-VLJ-CLF and POT-SED-NGK, covering the interval 1883-2008 (dark blue diamonds) for which we have data for these stations. Since 1957, the number of stations contributing to $I D V$ is high $(\sim 50)$ for every year, so the data is good. The open red squares show the same relationship for 1957-2008. 
IDV Derived Using Nighttime (blue) and Daytime (red) Differences

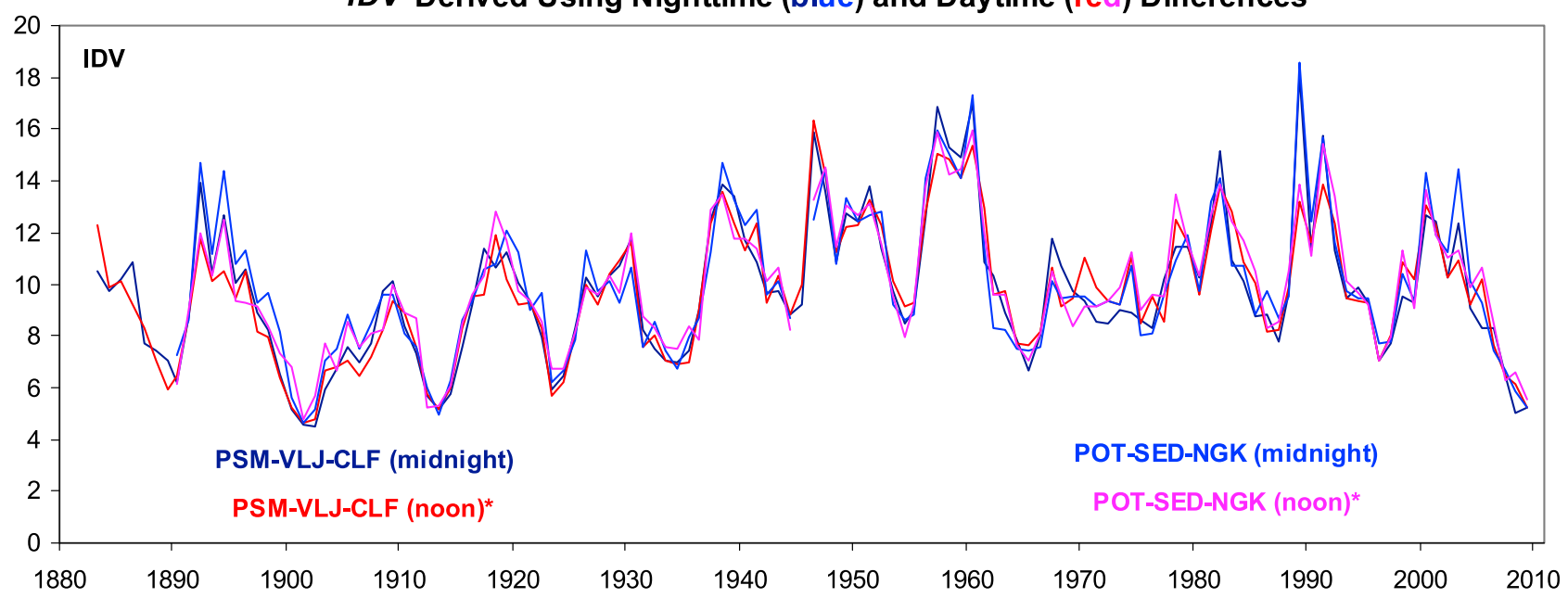

Figure 6. Raw $I D V$ derived using nighttime hourly data (blue) and daytime hourly data (red) for the French stations PSM-VLJ-CLF and the German stations POT-SED-NGK. The daytime values are $\sim 30 \%$ larger than the nighttime value because of day-to-day (non-solar) variations of the regular solar variations, $S_{R}$, and have been scaled to the same average as the nighttime values for easier comparison.

standard error of the mean of more than fifty stations is $0.1 \mathrm{nT}$.

[18] Figure 8 shows that the differences between IDV05 and IDV09 are slight, and due to the additional data since 1880. During the period of overlap (1872-2003, 2004 was only partial), the two time series agree within an RMS of $0.33 \mathrm{nT}$ or $3 \%$. The coefficient of determination for the correlation between IDV09 and IDV05 is $\mathrm{R}^{2}=0.984$. IDV is a robust index.

\subsubsection{Physical Interpretation of $I D V$ : Measure of the Energy in the Ring Current}

[19] Svalgaard and Cliver [2005] reported that IDV is closely correlated with the negative part of the $D_{s t}$-index based on data back to 1932 [Karinen and Mursula, 2005]. Svalgaard and Cliver [2006] extended that relationship back to 1905 using the 100 -year $D_{s t}$-series derived by Love [2007; J. J. Love, personal communication, 2006], and confirm it here using IDV09. Yearly averages of $D_{s t}$ (scaled to Kyoto $D_{s t}$; we use $D_{s t}$ here in a generic sense without

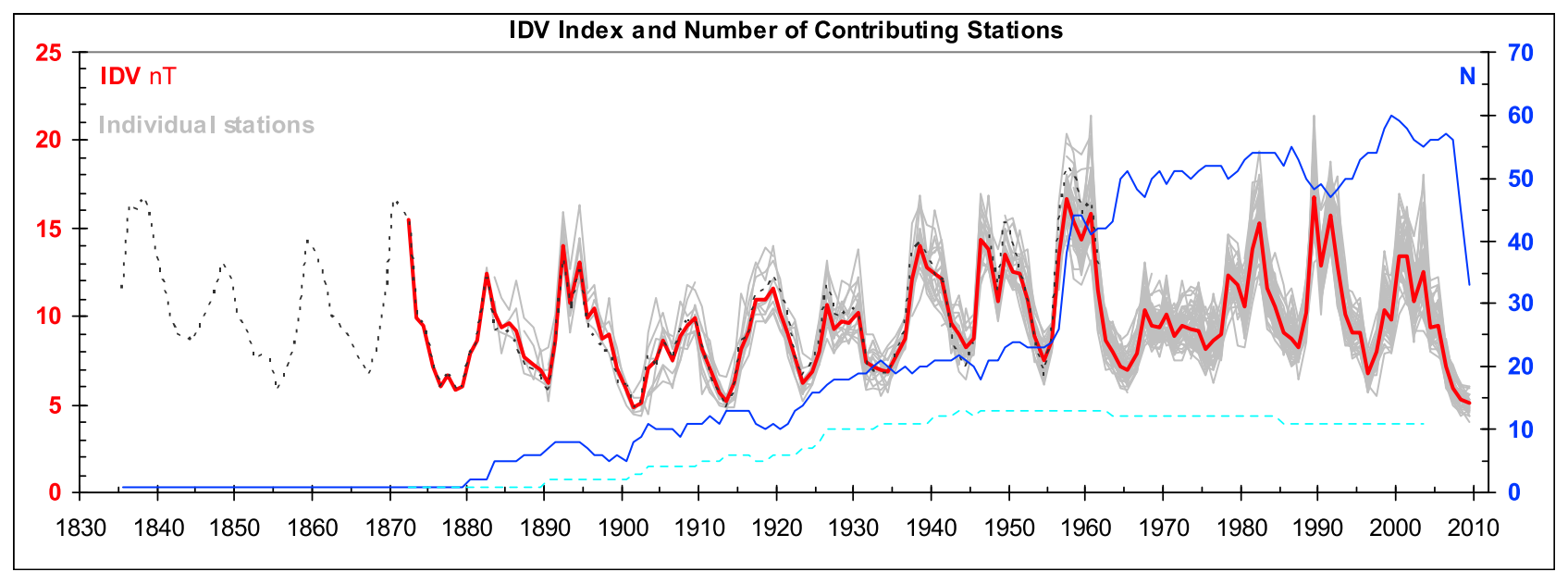

Figure 7. Yearly $I D V$-indices derived for individual stations (as given in Table 1) shown as gray curves. The red curve is a composite index calculated as the mean of the median and average values of the individual station values. This procedure may be justified by the very small difference between medians and averages $(0.16 \mathrm{nT}$ on average, see Figure 8$)$. The number, $N$, of contributing stations is shown by the thin blue curve and the corresponding number for IDV05 as a dashed light blue curve. The $u$-measure is considered a single station. A few station values differing more than five standard deviations from the average for a given year were omitted in calculating the average for that year. The dashed curve shows $I D V$ derived from the $u$-measure. 


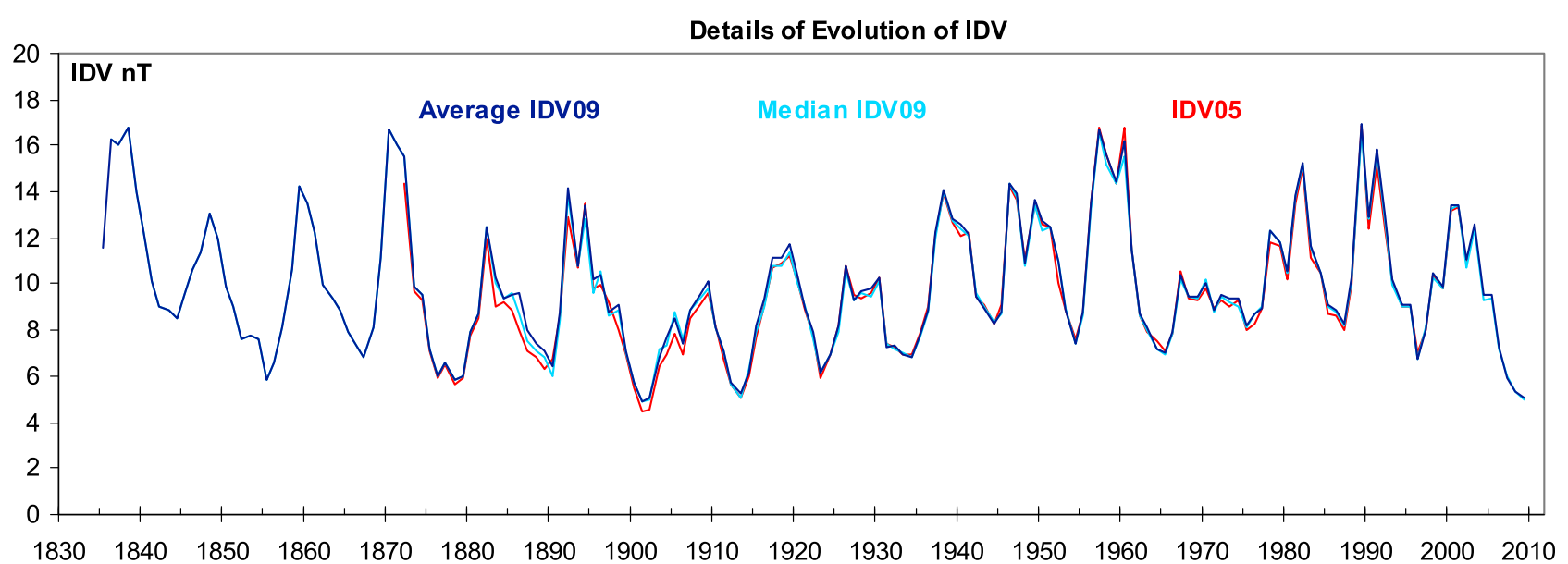

Figure 8. Average yearly values of IDV09 (dark blue curve) compared with median yearly values (light blue curve) and compared with published IDV05 (red curve).

distinguishing between different derivations of the underlying physical measure sought captured by $D_{s t}$ ) when the hourly value was negative were computed and found to be strongly correlated with $I D V\left(\mathrm{R}^{2}=0.91\right): I D V=-0.45\left(D_{s t}<\right.$ $0)$. Figure 9 compares IDV09 and $I D V$ computed from $D_{s t}$. The good match suggests that $I D V$ is a measure of the same physical reality as negative $D_{s t}$, namely the energy in the Ring Current, which then in turn seems to be controlled by HMF $B$ : $\left(D_{s t}<0\right)=4.81 B-9.41\left(\mathrm{R}^{2}=0.84\right)$, and we can then also use $D_{s t}$ to determine the HMF strength: $B=2.70-0.1736\left(D_{s t}<\right.$ $0)$. Schmidt [1926] actually suggested that in the definition of the $u$-measure it would be slightly better to only use the negative differences between consecutive days.

\subsection{Using IDV09 to Calculate HMF Strength, 1835-2009}

[20] Since the 2005 definition paper, lower values of HMF strength, $B$, have improved the dynamic range (and thus the statistical significance) of the correlation between $I D V$ and $B$. An approximate linear correlation was found, but there is no a priori reason the relationship would be strictly linear. In addition, it has been argued [Lockwood et al., 2006] that $B$ should be taken as the independent variable instead of IDV. Svalgaard and Cliver [2006] showed that it does not make much difference which way the correlation is evaluated. In the end, the RMS difference $(0.4 \mathrm{nT}$ or less than $\sim 10 \%$ ) between HMF $B$ observed in situ near the Earth and inferred from $I D V$ is what matters. (Using hourly averages from the OMNI dataset for historical data and from ACE for near real-time recent data.) The average coefficients for the linear correlation performed four ways (average, median, and for each: direct and inverse) are

$B(\mathrm{nT})=(2.06 \pm 0.21)+(0.441 \pm 0.021) I D V$

$\left(R^{2}=0.869\right)$

Negative $D_{s t}$ and IDV measure the same effect

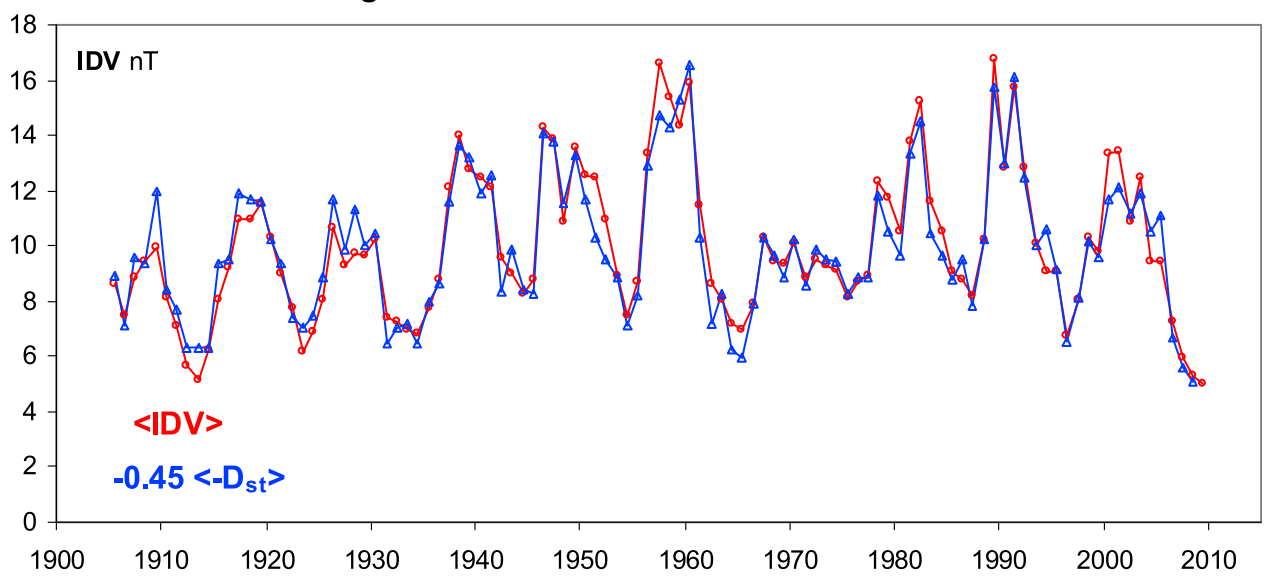

Figure 9. Yearly average values of $I D V$ and of $D_{s t}$ when it was less than zero (based on $D_{s t}$ from Kyoto WDC and on $D_{s t}$ from J. J. Love (personal communication, 2006) scaled to Kyoto levels). The "spike" in 1909 is due to the extremely strong storm on 25 September 1909 causing loss of data at all but one station (API), giving that one data point undue influence. To guard against the influence of such sporadic extreme values, the daily values of $I D V$ were capped at $75 \mathrm{nT}$. 
Table 2. $I D V$-Index Measured or Inferred for Each Year Since $1835^{\mathrm{a}}$

\begin{tabular}{|c|c|c|c|}
\hline Year & IDV09 & $I D V$ HMF $B$ & $\begin{array}{c}\text { Observed } \\
\text { HMF } B\end{array}$ \\
\hline 1835.5 & 11.60 & 7.23 & \\
\hline 1836.5 & 16.30 & 9.30 & \\
\hline 1837.5 & 16.00 & 9.17 & \\
\hline 1838.5 & 16.80 & 9.51 & \\
\hline 1839.5 & 14.00 & 8.30 & \\
\hline 1840.5 & 12.20 & 7.50 & \\
\hline 1841.5 & 10.10 & 6.55 & \\
\hline 1842.5 & 9.00 & 6.05 & \\
\hline 1843.5 & 8.90 & 6.00 & \\
\hline 1844.5 & 8.50 & 5.81 & \\
\hline 1845.5 & 9.50 & 6.28 & \\
\hline 1846.5 & 10.10 & 6.55 & \\
\hline 1847.5 & 11.40 & 7.14 & \\
\hline 1848.5 & 13.10 & 7.90 & \\
\hline 1849.5 & 12.00 & 7.41 & \\
\hline 1850.5 & 9.90 & 6.46 & \\
\hline 1851.5 & 9.00 & 6.05 & \\
\hline 1852.5 & 7.60 & 5.39 & \\
\hline 1853.5 & 7.80 & 5.48 & \\
\hline 1854.5 & 7.60 & 5.39 & \\
\hline 1855.5 & 5.80 & 4.51 & \\
\hline 1856.5 & 6.60 & 4.90 & \\
\hline 1857.5 & 7.20 & 5.19 & \\
\hline 1858.5 & 10.60 & 6.78 & \\
\hline 1859.5 & 14.30 & 8.43 & \\
\hline 1860.5 & 13.50 & 8.08 & \\
\hline 1861.5 & 12.20 & 7.50 & \\
\hline 1862.5 & 10.00 & 6.51 & \\
\hline 1863.5 & 9.40 & 6.23 & \\
\hline 1864.5 & 8.40 & 5.76 & \\
\hline 1865.5 & 7.90 & 5.53 & \\
\hline 1866.5 & 7.30 & 5.24 & \\
\hline 1867.5 & 6.80 & 5.00 & \\
\hline 1868.5 & 8.10 & 5.62 & \\
\hline 1869.5 & 11.10 & 7.01 & \\
\hline 1870.5 & 16.70 & 9.47 & \\
\hline 1871.5 & 16.00 & 9.17 & \\
\hline 1872.5 & 14.60 & 8.56 & \\
\hline 1873.5 & 9.90 & 6.46 & \\
\hline 1874.5 & 9.50 & 6.28 & \\
\hline 1875.5 & 7.20 & 5.19 & \\
\hline 1876.5 & 6.00 & 4.61 & \\
\hline 1877.5 & 6.60 & 4.90 & \\
\hline 1878.5 & 5.80 & 4.51 & \\
\hline 1879.5 & 6.00 & 4.61 & \\
\hline 1880.5 & 7.89 & 5.53 & \\
\hline 1881.5 & 8.69 & 5.90 & \\
\hline 1882.5 & 12.47 & 7.62 & \\
\hline 1883.5 & 10.20 & 6.60 & \\
\hline 1884.5 & 9.36 & 6.22 & \\
\hline 1885.5 & 9.57 & 6.22 & \\
\hline 1886.5 & 9.14 & 6.11 & \\
\hline 1887.5 & 7.75 & 5.46 & \\
\hline 1888.5 & 7.27 & 5.23 & \\
\hline 1889.5 & 6.99 & 5.09 & \\
\hline 1890.5 & 6.22 & 4.72 & \\
\hline 1891.5 & 8.60 & 5.86 & \\
\hline 1892.5 & 14.02 & 8.31 & \\
\hline 1893.5 & 10.79 & 6.87 & \\
\hline 1894.5 & 13.12 & 7.91 & \\
\hline 1895.5 & 9.95 & 6.48 & \\
\hline 1896.5 & 10.48 & 6.73 & \\
\hline 1897.5 & 8.71 & 5.91 & \\
\hline 1898.5 & 8.98 & 6.04 & \\
\hline 1899.5 & 7.06 & 5.13 & \\
\hline 1900.5 & 5.75 & 4.49 & \\
\hline 1901.5 & 4.90 & 4.06 & \\
\hline 1902.5 & 5.04 & 4.13 & \\
\hline 1903.5 & 7.03 & 5.11 & \\
\hline
\end{tabular}

Table 2. (continued)

\begin{tabular}{|c|c|c|c|}
\hline Year & IDV09 & $I D V$ HMF $B$ & $\begin{array}{c}\text { Observed } \\
\text { HMF } B\end{array}$ \\
\hline 1904.5 & 7.54 & 5.36 & \\
\hline 1905.5 & 8.62 & 5.87 & \\
\hline 1906.5 & 7.49 & 5.33 & \\
\hline 1907.5 & 8.83 & 5.97 & \\
\hline 1908.5 & 9.45 & 6.26 & \\
\hline 1909.5 & 9.95 & 6.48 & \\
\hline 1910.5 & 8.10 & 5.63 & \\
\hline 1911.5 & 7.08 & 5.14 & \\
\hline 1912.5 & 5.69 & 4.46 & \\
\hline 1913.5 & 5.15 & 4.18 & \\
\hline 1914.5 & 6.22 & 4.72 & \\
\hline 1915.5 & 8.09 & 5.62 & \\
\hline 1916.5 & 9.19 & 6.13 & \\
\hline 1917.5 & 10.95 & 6.94 & \\
\hline 1918.5 & 10.97 & 6.95 & \\
\hline 1919.5 & 11.57 & 7.22 & \\
\hline 1920.5 & 10.28 & 6.64 & \\
\hline 1921.5 & 8.97 & 6.03 & \\
\hline 1922.5 & 7.74 & 5.45 & \\
\hline 1923.5 & 6.17 & 4.70 & \\
\hline 1924.5 & 6.89 & 5.04 & \\
\hline 1925.5 & 8.05 & 5.60 & \\
\hline 1926.5 & 10.69 & 6.82 & \\
\hline 1927.5 & 9.29 & 6.18 & \\
\hline 1928.5 & 9.69 & 6.37 & \\
\hline 1929.5 & 9.64 & 6.34 & \\
\hline 1930.5 & 10.22 & 6.61 & \\
\hline 1931.5 & 7.38 & 5.28 & \\
\hline 1932.5 & 7.22 & 5.21 & \\
\hline 1933.5 & 6.96 & 5.08 & \\
\hline 1934.5 & 6.83 & 5.02 & \\
\hline 1935.5 & 7.75 & 5.46 & \\
\hline 1936.5 & 8.81 & 5.96 & \\
\hline 1937.5 & 12.11 & 7.46 & \\
\hline 1938.5 & 14.02 & 8.31 & \\
\hline 1939.5 & 12.79 & 7.77 & \\
\hline 1940.5 & 12.48 & 7.63 & \\
\hline 1941.5 & 12.10 & 7.46 & \\
\hline 1942.5 & 9.57 & 6.31 & \\
\hline 1943.5 & 8.97 & 6.03 & \\
\hline 1944.5 & 8.28 & 5.71 & \\
\hline 1945.5 & 8.75 & 5.93 & \\
\hline 1946.5 & 14.33 & 8.44 & \\
\hline 1947.5 & 13.85 & 8.24 & \\
\hline 1948.5 & 10.87 & 6.91 & \\
\hline 1949.5 & 13.55 & 8.10 & \\
\hline 1950.5 & 12.56 & 7.66 & \\
\hline 1951.5 & 12.46 & 7.62 & \\
\hline 1952.5 & 10.97 & 6.95 & \\
\hline 1953.5 & 8.90 & 6.00 & \\
\hline 1954.5 & 7.46 & 5.32 & \\
\hline 1955.5 & 8.69 & 5.90 & \\
\hline 1956.5 & 13.38 & 8.02 & \\
\hline 1957.5 & 16.65 & 9.45 & \\
\hline 1958.5 & 15.42 & 8.92 & \\
\hline 1959.5 & 14.39 & 8.47 & \\
\hline 1960.5 & 15.87 & 9.11 & \\
\hline 1961.5 & 11.49 & 7.18 & \\
\hline 1962.5 & 8.62 & 5.87 & \\
\hline 1963.5 & 8.06 & 5.60 & 5.45 \\
\hline 1964.5 & 7.19 & 5.19 & 5.12 \\
\hline 1965.5 & 6.93 & 5.07 & 5.06 \\
\hline 1966.5 & 7.88 & 5.52 & 6.00 \\
\hline 1967.5 & 10.30 & 6.65 & 6.36 \\
\hline 1968.5 & 9.47 & 6.26 & 6.19 \\
\hline 1969.5 & 9.39 & 6.23 & 6.05 \\
\hline 1970.5 & 10.12 & 6.56 & 6.35 \\
\hline 1971.5 & 8.84 & 5.97 & 6.00 \\
\hline 1972.5 & 9.49 & 6.27 & 6.38 \\
\hline 1973.5 & 9.28 & 6.18 & 6.35 \\
\hline 1974.5 & 9.18 & 6.13 & 6.63 \\
\hline
\end{tabular}


Table 2. (continued)

\begin{tabular}{|c|c|c|c|}
\hline Year & IDV09 & $I D V$ HMF $B$ & $\begin{array}{c}\text { Observed } \\
\text { HMF } B\end{array}$ \\
\hline 1975.5 & 8.15 & 5.65 & 5.82 \\
\hline 1976.5 & 8.70 & 5.91 & 5.45 \\
\hline 1977.5 & 8.96 & 6.03 & 5.85 \\
\hline 1978.5 & 12.32 & 7.56 & 7.08 \\
\hline 1979.5 & 11.78 & 7.32 & 7.59 \\
\hline 1980.5 & 10.51 & 6.74 & 6.98 \\
\hline 1981.5 & 13.78 & 8.20 & 7.84 \\
\hline 1982.5 & 15.25 & 8.84 & 8.81 \\
\hline 1983.5 & 11.60 & 7.23 & 7.61 \\
\hline 1984.5 & 10.50 & 6.74 & 7.32 \\
\hline 1985.5 & 9.06 & 6.07 & 5.89 \\
\hline 1986.5 & 8.80 & 5.95 & 5.74 \\
\hline 1987.5 & 8.20 & 5.67 & 6.09 \\
\hline 1988.5 & 10.21 & 6.61 & 7.30 \\
\hline 1989.5 & 16.74 & 9.48 & 8.15 \\
\hline 1990.5 & 12.84 & 7.79 & 7.29 \\
\hline 1991.5 & 15.77 & 9.07 & 9.34 \\
\hline 1992.5 & 12.87 & 7.80 & 8.25 \\
\hline 1993.5 & 10.08 & 6.54 & 6.59 \\
\hline 1994.5 & 9.06 & 6.07 & 6.15 \\
\hline 1995.5 & 9.08 & 6.08 & 5.72 \\
\hline 1996.5 & 6.76 & 4.98 & 5.11 \\
\hline 1997.5 & 8.06 & 5.60 & 5.51 \\
\hline 1998.5 & 10.34 & 6.66 & 6.89 \\
\hline 1999.5 & 9.82 & 6.42 & 6.91 \\
\hline 2000.5 & 13.36 & 8.02 & 7.18 \\
\hline 2001.5 & 13.44 & 8.05 & 6.94 \\
\hline 2002.5 & 10.90 & 6.92 & 7.64 \\
\hline 2003.5 & 12.51 & 7.64 & 7.60 \\
\hline 2004.5 & 9.42 & 6.24 & 6.53 \\
\hline 2005.5 & 9.44 & 6.25 & 6.25 \\
\hline 2006.5 & 7.22 & 5.21 & 5.03 \\
\hline 2007.5 & 5.96 & 4.59 & 4.48 \\
\hline 2008.5 & 5.29 & 4.25 & 4.23 \\
\hline 2009.5 & 5.04 & 4.13 & 4.05 \\
\hline 2010.2 & 5.50 & 4.45 & 4.95 \\
\hline
\end{tabular}

${ }^{\text {a }}$ The HMF strength $B$ at the Earth is derived from $I D V$ as per section 2.2 . The field observed in situ (OMNI and ACE data sets) is given for comparison. A few years had very incomplete data coverage and missing data were derived by linear interpolation across data gaps to avoid uneven coverage skewing the average. Those values are in italics.
The equivalent power law dependence comes to

$$
B(\mathrm{nT})=(1.33 \pm 0.07) I D V^{0.689 \pm 0.023}\left(\mathrm{R}^{2}=0.905\right)
$$

The adopted values for $B$ inferred from IDV09 given in Table 2 are the mean values calculated using these two relationships. Data Set S3 in the auxiliary material summarizes the coefficients for all correlations. The 'error bars' quoted are not a measure of the statistical significance of the correlations in a strict sense, but are solely indicative of the range or variability of the various coefficients.

[21] Figure 10 shows the values for HMF $B$ inferred from $I D V$ from 1835 to the present (blue curve) and $B$ measured by spacecraft (red curve). A 4th-order polynomial fit suggests a $\sim 100$ year Gleissberg cycle. Cycle 23 looks remarkably like cycle 13 , including the very deep solar minimum following both cycles, likely presaging a weak cycle 24 as predicted from the solar polar fields [Svalgaard et al., 2005; Schatten, 2005]. It is clear that we are returning to conditions prevailing a century ago. It seems likely that other solar parameters such as Total Solar Irradiance [Fröhlich, 2009; Steinhilber et al., 2009] and cosmic ray modulation [Steinhilber et al., 2010] are reverting to similar conditions with possible implications for the climate-change debate.

\subsection{Comparison of IDV09-Based $B$ With Other Recent Reconstructions}

\subsubsection{Consilience of Reconstructions Based on Geomagnetic Data}

[22] Reconstructions of HMF $B$ have been discordant in the past (e.g., Svalgaard [1977], as referenced by Schatten et al. [1978], Andreasen [1997], Lockwood et al. [1999, 2006], and Svalgaard and Cliver [2005, 2006, 2007b]). The realization [Svalgaard et al., 2003] that geomagnetic indices can be constructed that have different dependencies on $B$ and solar wind speed $(V)$ has enabled robust determinations of both $V$ [Svalgaard and Cliver, 2007b; Rouillard et al., 2007; Lockwood et al., 2009] and B [Svalgaard and Cliver, 2005, 2006; Lockwood et al., 2009] that have converged to a common, well-constrained data set. Progress has

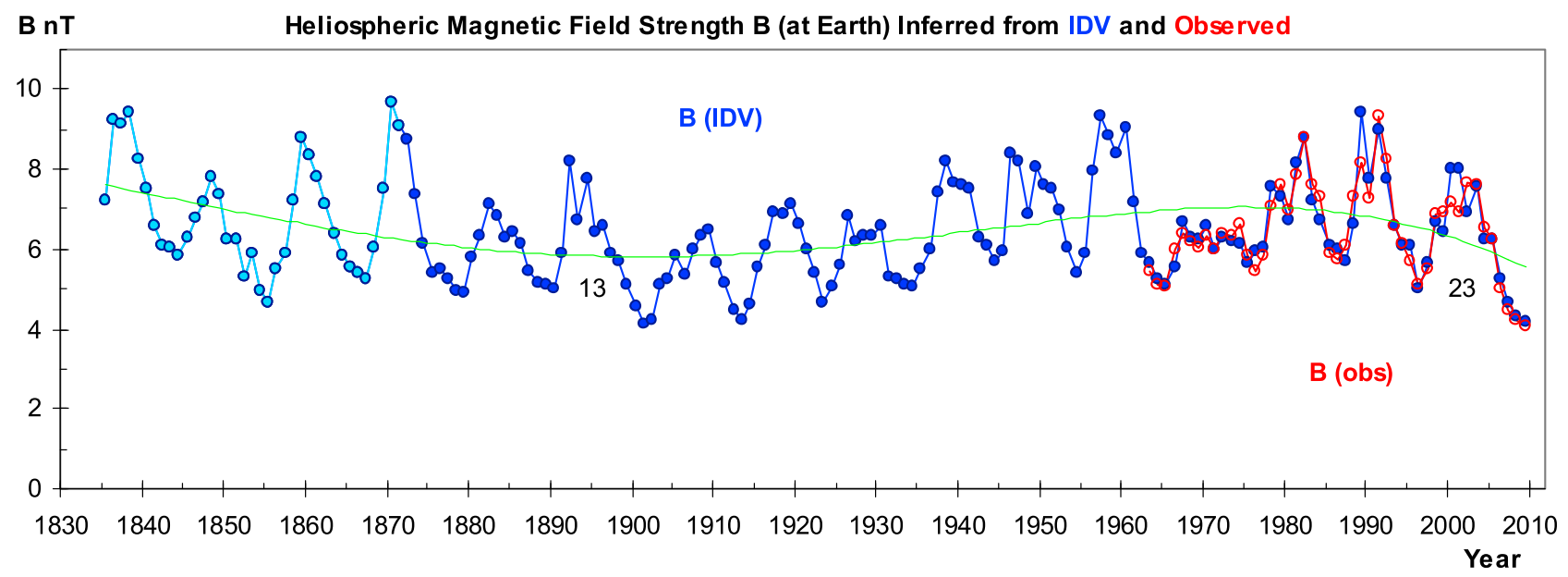

Figure 10. Yearly average values of the HMF $B$ inferred from the $I D V$-index (dark blue curve) and from the early $u$-measure (light blue curve) compared with in situ measurements (red curve). There is a hint of the $\sim 100$ year Gleissberg cycle. 


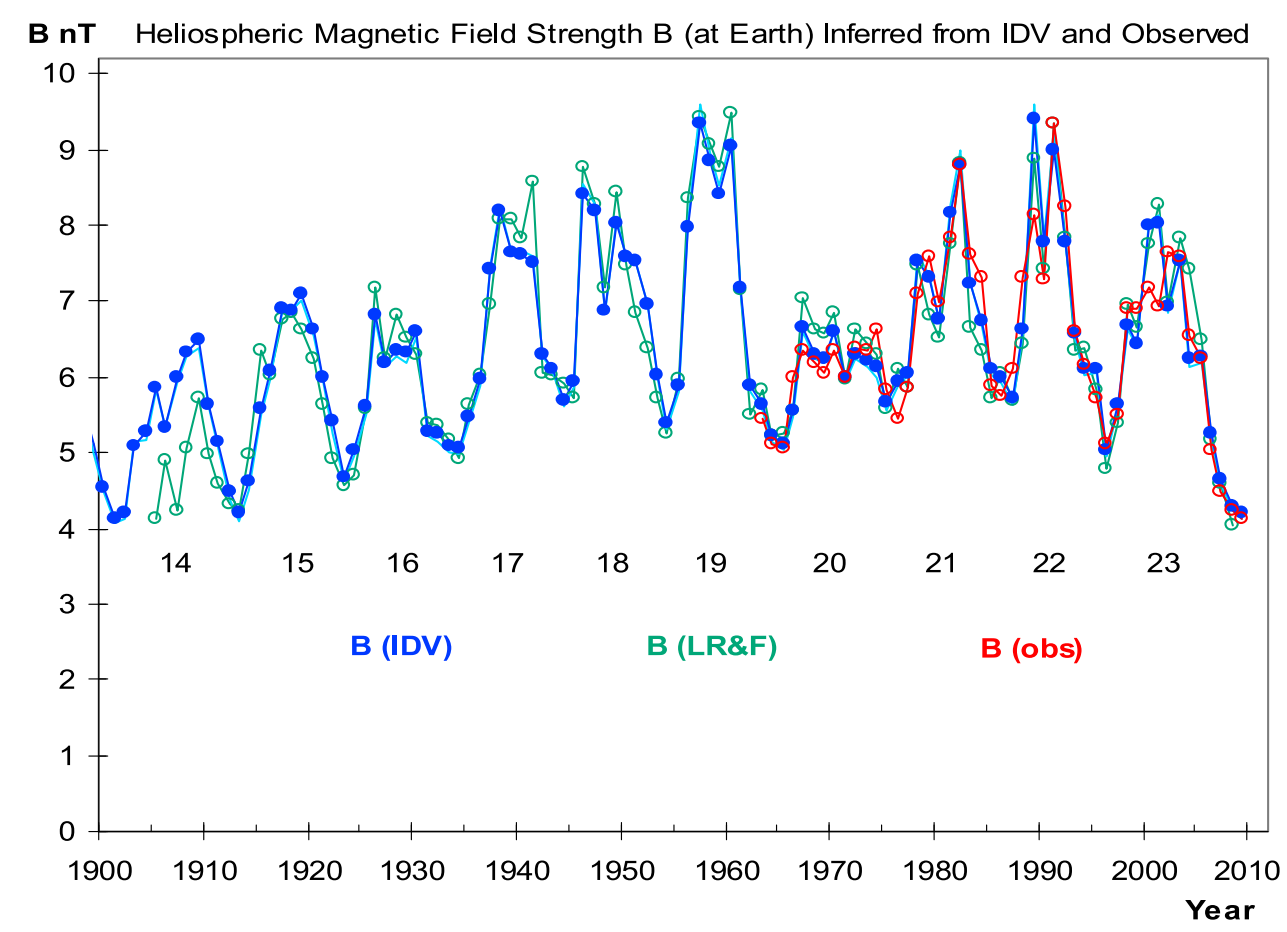

Figure 11. Comparison of HMF $B$ determined from $I D V$ (light blue curve using equation (3) and dark blue curve using equation (2)), by Lockwood et al. [2009] (green curve), and observed by spacecraft (red curve).

been swift and Figure 11 shows the convergence of HMF $B$ determined by Lockwood et al. [2009] to the values determined from IDV [Svalgaard and Cliver, 2005; this paper]. The Lockwood et al. [2009, and references therein] reconstruction is still discordant from ours for a few years during solar cycle 14 , but apart from that, the agreement is quite remarkable and the issues seem resolved.

[23] Figure 12 details the evolution of the various determinations of $B$ since the influential, but now superseded, Lockwood et al. [1999] paper. It is clear that we now possess the methodology to infer B with good accuracy as far back

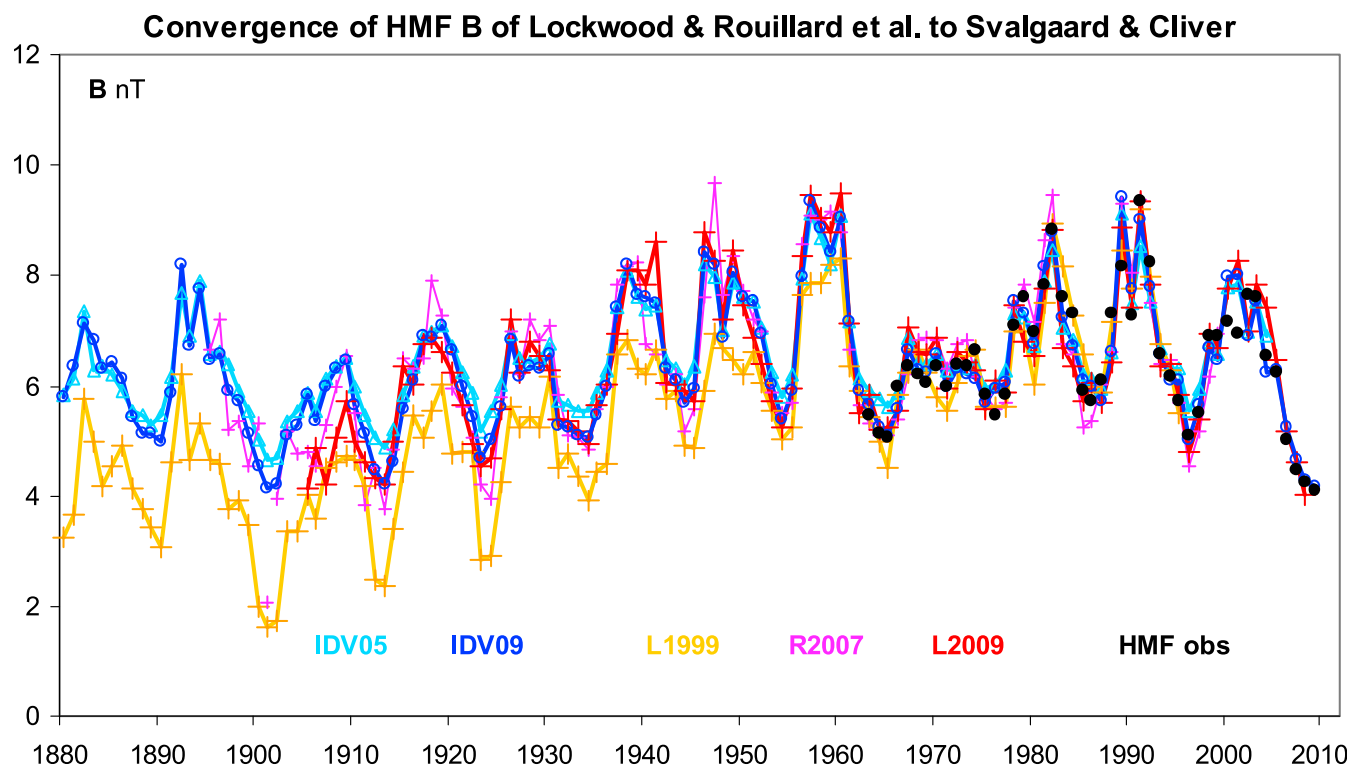

Figure 12. Comparison between HMF $B$ derived by Svalgaard and Cliver [2005] (light blue curve and open circles); this paper (dark blue curve and open circles); and HMF B derived by Lockwood et al. [1999] (orange curve and pluses), Rouillard et al. [2007] (their point for 1901 was in error) and A. Rouillard (personal communication, 2007) (pink curve and pluses), and Lockwood et al. [2009] (red curve and pluses), matched to in situ observations of $B$ (black dots). 
Heliospheric Magnetic Field Comparisons

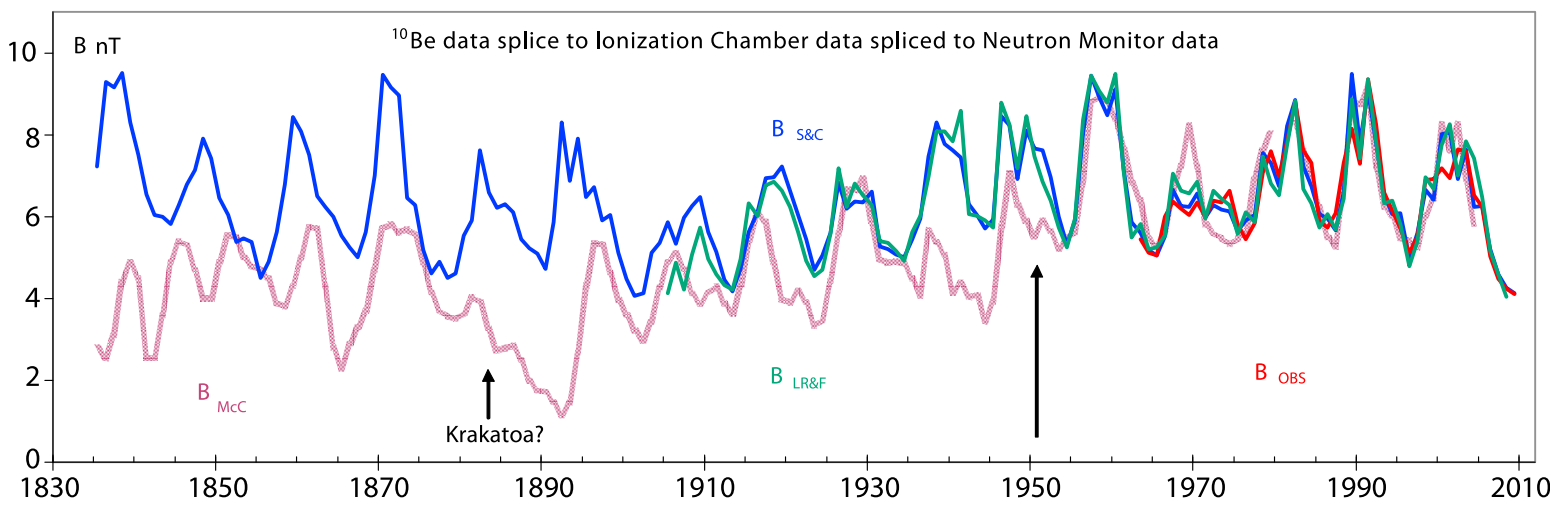

Figure 13. Yearly averages of near-Earth HMF $B$ inferred by this paper (blue curve $B_{\mathrm{S} \& \mathrm{C}}$ ), by Lockwood et al. [2009] (green curve $B_{\mathrm{LR} \& \mathrm{~F}}$ ), observed by spacecraft (red curve $B_{\mathrm{OBS}}$ ) compared to $B$ inferred by McCracken [2007] (purple curve $B_{\mathrm{McC}}$ ). The large arrow marks the beginning of the neutron monitor-based part of the record. One might speculate that the extremely low values during 1883-1893 are caused by the explosion of Krakatoa ejecting sulfur-rich aerosols into the stratosphere influencing the deposition of ${ }^{10} \mathrm{Be}$.

as continuous geomagnetic records of $H$ reach. A concerted effort of digitization of 19th century yearbook records would promise to further improve our knowledge of the magnetic field in the heliosphere.

[24] Svalgaard and Cliver [2007a] argued for a floor in yearly averages of solar wind $B$ which was approached at every 11-yr minimum and represented the ground-state of the Sun during extended minima such as the Maunder Minimum. With the larger dynamic range afforded by the current minimum, we can now refine the value of the floor to be closer to the $\sim 4 \mathrm{nT}$ observed during 2008 and 2009 [see also Owens et al., 2008], returning to the values inferred for 11-yr minima during the previous Gleissberg minimum at the turn of the 20th century.

\subsubsection{Comparison With ${ }^{10} \mathrm{Be}-$ Based Reconstructions}

[25] McCracken [2007] spliced together ${ }^{10} \mathrm{Be}$ data, ionization-chamber cosmic ray data (calibrated with balloon flight data), and neutron monitor cosmic ray data to produce an 'equivalent' neutron monitor count series covering the entire interval $1428-2005$, and inverted the series for $B$ in order to express the data in terms of the HMF $B$. In Figure 13 we compare his series for HMF $B$ with the 'consensus' $B$ from geomagnetic data.

[26] In McCracken's time series for $B$, a large step-like change $(1.7 \mathrm{nT}$; from $3.5 \mathrm{nT}$ to $5.2 \mathrm{nT}$; the largest jump in the entire $\sim 600$-year record) occurs between the 1944 and 1954 sunspot minima flanking cycle 18. No such corresponding change is observed in the concordant reconstructions of Svalgaard and Cliver [2005; this paper], Rouillard et al. [2007], and Lockwood et al. [2009], nor in B calculated from the quantity $B V$ deduced by Le Sager and Svalgaard [2004] using either $V$ of Svalgaard and Cliver [2006] or of Rouillard et al. [2007], or in $B$ deduced from $D_{s t}$.

[27] Muscheler et al. [2007] discuss the uncertainties with the balloon-borne data that form the basis for McCracken's calibration of the composite equivalent neutron monitor data before 1951. The strong geomagnetic evidence argues that this particular calibration of the pre-neutron monitor cosmic ray reconstruction is not on a firm footing. We suggest that part of the reason for the disagreement might lie with the

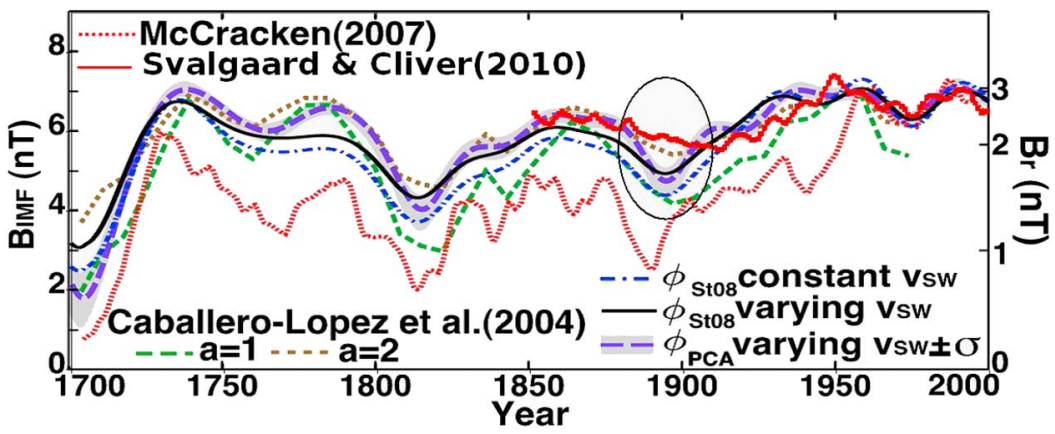

Figure 14. Comparison of our reconstruction of HMF $B$ (red curve, 25 year running means) with other reconstructions as reported by Steinhilber et al. [2010, Figure 7] (adapted and reproduced here), e.g., with their 25-year running mean of their PCA-based reconstruction (purple dashed curve) of $B$. The oval outlines an area of disagreement for which sufficient geomagnetic data exists that may be used to resolve the discrepancy. 
IDV and HMF B 1880-1920 (All stations)

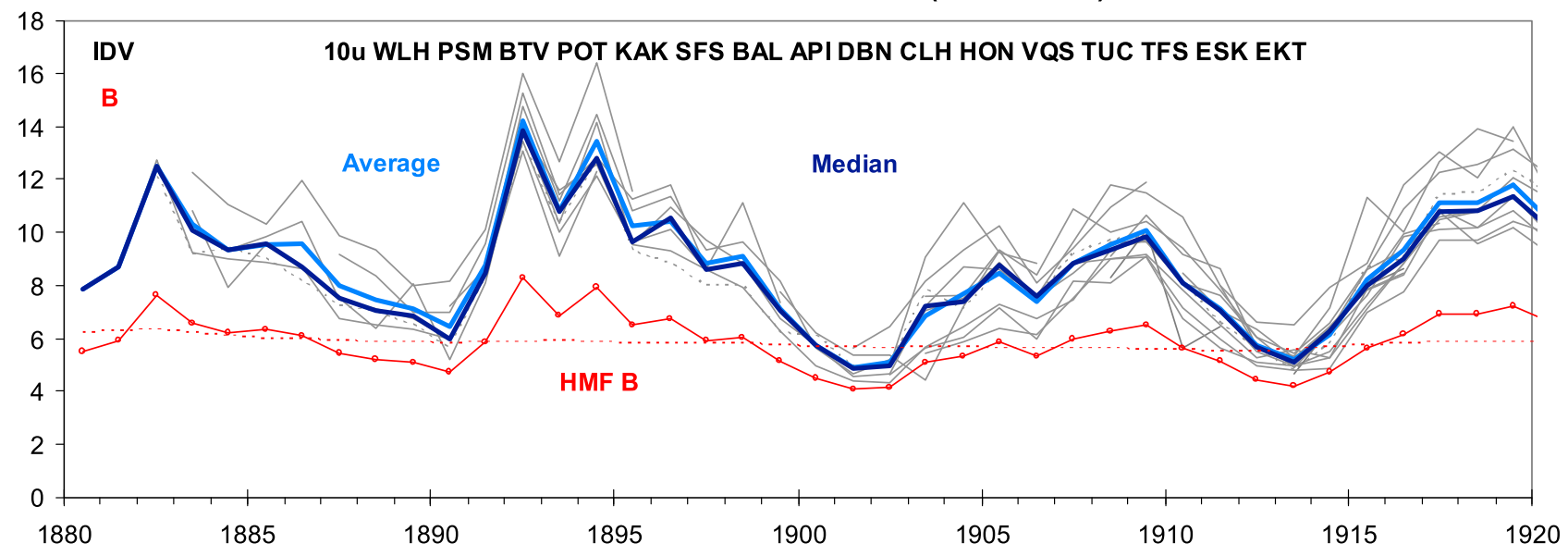

Figure 15. IDV (blue curves) and inferred HMF B (red curve; dashed line: 25-year running mean) 18801920 for all stations (as noted by their IAGA designations - $10 u$ shown as a dashed gray curve) where good geomagnetic data are available so far.

calibration and splicing together of the disparate cosmic ray data sets.

[28] After our paper was submitted, we were pleased to read a paper by Steinhilber et al. [2010] in which a new ${ }^{10} \mathrm{Be}$-based reconstruction has moved closer to our reconstruction, to that of Rouillard et al. [2007], and to that of Caballero-Lopez et al. [2004] with diffusion coefficient depending inversely of $B^{2}(a \sim 2)$. The reconstruction of Steinhilber et al. [2010] still differs somewhat with the geomagnetic based reconstructions, especially for the $\sim 1880-1900$ interval (Figure 14) and, just like the previous discrepancy, this will need to be resolved. We suggest that if the sharp dip around 1895 is not borne out by further investigation, the magnitude of earlier excursions to very low values may also be in doubt. Figure 15 shows $I D V$ for all stations for the interval 1880-1920 and does not support the marked decrease around $\sim 1895$. It is unlikely that data from further stations will change that conclusion. In line with this conclusion, W. R. Webber et al. (A comparison of new calculations of the yearly ${ }^{10}$ Be production in the Earth's polar atmosphere by cosmic rays with yearly ${ }^{10} \mathrm{Be}$ measurements in multiple Greenland ice cores between 1939 and 1994-A troubling lack of concordance, manuscript in preparation, 2010) suggest that "more than $50 \%$ of the ${ }^{10} \mathrm{Be}$ flux increase around, e.g., 1700 A.D., 1810 A.D. and 1895 A.D. is due to nonproduction related increases."

\section{Summary and Discussion}

[29] We have extended our 1872-2004 HMF time series [Svalgaard and Cliver, 2005] to the years 1835-2009 (Figure 10). The 1835-1871 interval is based on Bartels' $u$-measure, which he extended from 1871 back to 1835 using Wolf's [1884] Declination index based on several European stations and Moos' [1910] Summed Ranges from Colaba. The 1872-2009 interval is based on the $I D V$-index, with significantly more data for the early years (18721910). The forward extension of the HMF series through 2009 is important because the years 2007-2009 witnessed the lowest annual averages of $I D V$ during the space age. For the time of overlap between the re-evaluated $I D V$-index (IDV09) and IDV05, the difference is very small, testifying to the robustness of the index.

[30] A comparison of IDV09-based HMF strength with those obtained by other investigators using various combinations and permutations of geomagnetic indices revealed a pleasing agreement (Figure 11) in what had been previously a contentious field of research (Figures 12 and 13). The technique proposed by Svalgaard et al. [2003] and adopted by Rouillard et al. [2007] to use indices with different dependencies on $B$ and $V$ to separate these variables has proven out and allowed the vast storehouse of hourly and daily data to be brought to bear. In particular, the $B$ values deduced and cross-checked [Le Sager and Svalgaard, 2004] by this method have substantiated the approach made possible by the $I D V$-index as well as, as Svalgaard and Cliver [2005] suggested and has confirmed here, the negative component of the $D_{s t}$-index (Figure 9). We conclude that the long-term variation of heliospheric $B$ is firmly constrained during the time for which it is based on hourly values of $H$, and that current values at the solar minimum between cycles 23 and 24 are back to where they were 108 years ago at the solar minimum between cycles 13 and 14 .

[31] Although the recent reconstruction of $B$ based on ${ }^{10} \mathrm{Be}$ data [Steinhilber et al., 2010] generally agrees well with the geomagnetic-based reconstruction there is disagreement for the decade just prior to 1900 (Figure 14). Further examination of these years is critical because they present the only example during the 175 year interval of geomagnetic-based $B$ where the floor [Svalgaard and Cliver, 2007a] in the solar wind is challenged by Steinhilber et al. [2010], a challenge not supported by the geomagnetic evidence (Figure 15).

[32] Acknowledgments. Geomagnetic data has been downloaded from the World Data Centers for Geomagnetism in Kyoto, Japan, and Copenhagen, Denmark (now defunct), and from INTERMAGNET at http://www. 
intermagnet.org/Data_e.html. The research results presented in this paper rely on the data collected at magnetic observatories worldwide, and we thank the national institutions that support them. We also recognize the role of the INTERMAGNET program in promoting high standards of magnetic observatory practice. We thank the many people worldwide who have helped us with collection of data and metadata in addition to what is available from public sources. We thank Vladimir Papitashvili for the program to calculate corrected geomagnetic coordinates using the GUFM1 coefficients (courtesy of Catherine Constable). The OMNI data set was downloaded from http://omniweb.gsfc.nasa.gov/. Real-time ACE interplanetary data is downloaded from http://www.swpc.noaa.gov/ftpmenu/lists/ace2. html.

[33] Philippa Browning thanks the reviewers for their assistance in evaluating this manuscript.

\section{References}

Andreasen, G. K. (1997), Reconstruction of past solar wind variations: Inversion of the geomagnetic response at Godhavn, J. Geophys. Res., 102(A4), 7025-7036, doi:10.1029/96JA03161.

Bartels, J. (1932), Terrestrial-magnetic activity and its relations to solar phenomena, Terr. Magn. Atmos. Electr., 37(1), 1-52, doi:10.1029/ TE037i001p00001.

Caballero-Lopez, R. A., H. Moraal, K. G. McCracken, and F. B. McDonald (2004), The heliospheric magnetic field from 850 to $2000 \mathrm{AD}$ inferred from ${ }^{10}$ Be records, J. Geophys. Res., 109, A12102, doi:10.1029/ 2004JA010633.

Fröhlich, C. (2009), Evidence of a long-term trend in total solar irradiance, Astron. Astrophys., 501(3), L27-L30, doi:10.1051/0004-6361/ 200912318

Glassmeier, K., J. Vogt, A. Stadelmann, and S. Buchert (2004), Concerning long-term geomagnetic variations and space climatology, Ann. Geophys. 22(10), 3669-3677, doi:10.5194/angeo-22-3669-2004.

Hoyt, D. V., K. H. Schatten, and E. Nesmes-Ribes (1994), The one hundredth year of Rudolf Wolf's death: Do we have the correct reconstruction of solar activity? Geophys. Res. Lett., 21(18), 2067-2070, doi:10.1029/94GL01698

Joos, G., J. Bartels, and P. Ten Bruggencate (1952), Landolt-Börnstein: Zahlenwerte und funktionen aus physik, chemie, astronomie, geophysik und technik, in Astronomie und Geophysik, vol. 18, Springer, New York.

Karinen, A., and K. Mursula (2005), A new reconstruction of the $D_{s t}$ index for 1932-2002, Ann. Geophys., 23(2), 475-485, doi:10.5194/angeo-23475-2005.

Kertz, W. (1958), Ein neues mass für die feldstärke des erdmagnetischen äquatorialen Ringstroms, Abh. Akad. Wiss. Goettingen Math. Phys., 2, $1-83$.

Le Sager, P., and L. Svalgaard (2004), No increase of the interplanetary electric field since 1926, J. Geophys. Res., 109, A07106, doi:10.1029/ 2004JA010411.

Lockwood, M., R. Stamper, and M. N. Wild (1999), A doubling of the Sun's coronal magnetic field during the past 100 years, Nature399, 437-439, doi:10.1038/20867.

Lockwood, M., A. P. Rouillard, I. Finch, and R. Stamper (2006), Comment on "The $I D V$ index: Its derivation and use in inferring long-term variations of the interplanetary magnetic field strength" by Leif Svalgaard and Edward W. Cliver, J. Geophys. Res., 111, A09109, doi:10.1029/ 2006JA011640.

Lockwood, M., A. P. Rouillard, and I. D. Finch (2009), The rise and fall of open solar flux during the current grand solar maximum, Astrophys. J., 700, 937-944, doi:10.1088/0004-6 37X/700/2/937.

Love, J. J. (2007), A continuous long-term record of magnetic-storm occurrence and intensity, Eos Trans. $A G U, 88(23)$, Jt. Assem. Suppl., Abstract SH54B-03.

Mayaud, P. N. (1980), Derivation, Meaning, and Use of Geomagnetic Indices, Geophys. Monogr. Ser., vol. 22, 154 pp., AGU, Washington, D. C. McCracken, K. G. (2007), Heliomagnetic field near Earth, 1428-2005, J. Geophys. Res., 112, A09106, doi:10.1029/2006JA012119.
Moos, N. A. F. (1910), Colaba Magnetic Data, 1846 to 1905. 2. The Phenomenon and its Discussion, 782 pp., Cent. Gov. Press, Bombay, India. Muscheler, R., F. Joos, J. Beer, S. A. Müller, M. Vonmoos, and I. Snowball (2007), Solar activity during the last $1000 \mathrm{yr}$ inferred from radionuclide records, Quat. Sci. Rev., 26, 82-97, doi:10.1016/j.quascirev.2006.07.012.

Owens, M. J., N. U. Crooker, N. A. Schwadron, T. S. Horbury, S. Yashiro, H. Xie, O. C. St. Cyr, and N. Gopalswamy (2008), Conservation of open solar magnetic flux and the floor in the heliospheric magnetic field, Geophys. Res. Lett., 35, L20108, doi:10.1029/2008GL035813.

Rouillard, A. P., M. Lockwood, and I. Finch (2007), Centennial changes in the solar wind speed and in the open solar flux, J. Geophys. Res., 112, A05103, doi:10.1029/2006JA012130.

Schatten, K. H. (2005), Fair space weather for solar cycle 24, Geophys. Res. Lett., 32, L21106, doi:10.1029/2005GL024363.

Schatten, K. H., P. H. Scherrer, L. Svalgaard, and J. M. Wilcox (1978), Using dynamo theory to predict the sunspot number during solar cycle 21, Geophys. Res. Lett., 5(5), 411-414, doi:10.1029/GL005i005p00411.

Schmidt, A. (1926), Archiv des erdmagnetismus, Heft 4, Georg Reimer, Berlin.

Steinhilber, F., J. Beer, and C. Fröhlich (2009), Total solar irradiance during the Holocene,Geophys. Res. Lett., 36, L19704, doi:10.1029/ 2009GL040142.

Steinhilber, F., J. A. Abreu, J. Beer, and K. G. McCracken (2010), Interplanetary magnetic field during the past 9300 years inferred from cosmogenic radionuclides, J. Geophys. Res., 115, A01104, doi:10.1029/ 2009JA014193.

Svalgaard, L. (1977), Geomagnetic activity: Dependence on solar wind parameters, in Skylab Workshop Monograph on Coronal Holes, edited by J. B. Zirker, pp. 371-436, Colo. Assoc. Univ. Press, Boulder, Colo.

Svalgaard, L. (2005), Re-derivation of $D_{s t}$, Eos Trans. $A G U, 86(52)$, Fall Meet. Suppl., Abstract SA12A-04.

Svalgaard, L. (2009), Observatory data: A 170-year Sun-Earth connection, in Proceedings of the XIIIth IAGA Workshop on Geomagnetic Observatory Instruments, Data Acquisition, and Processing, edited by J. J. Love. pp. 246-257, U.S. Geol. Surv., Reston, Va.

Svalgaard, L., and E. W. Cliver (2005), The IDV index: Its derivation and use in inferring long-term variations of the interplanetary magnetic field strength, J. Geophys. Res., 110, A12103, doi:10.1029/2005JA011203.

Svalgaard, L., and E. W. Cliver (2006), Reply to the comment by M. Lockwood et al. on "The $I D V$ index: Its derivation and use in inferring longterm variations of the interplanetary magnetic field strength," J. Geophys. Res., 111, A09110, doi:10.1029/2006JA011678.

Svalgaard, L., and E. W. Cliver (2007a), A floor in the solar wind magnetic field, Astrophys. J., 661, L203-L206, doi:10.1086/518786.

Svalgaard, L., and E. W. Cliver (2007b), Interhourly variability index of geomagnetic activity and its use in deriving the long-term variation of solar wind speed, J. Geophys. Res., 112, A10111, doi:10.1029/ 2007JA012437.

Svalgaard, L., E. W. Cliver, and P. Le Sager (2003), Determination of interplanetary magnetic field strength, solar wind speed, and EUV irradiance, 1890-2003, Eur. Space Agency Spec. Publ., ESA SP-535, 15-23.

Svalgaard, L., E. W. Cliver, and Y. Kamide (2005), Sunspot cycle 24: Smallest cycle in 100 years? Geophys. Res. Lett., 32, L01104, doi:10.1029/2004GL021664

Wang, Y.-M., and N. R. Sheeley Jr. (2003), On the fluctuating component of the Sun's large-scale magnetic field, Astrophys. J., 590, 1111-1120, doi:10.1086/375026.

Wang, Y.-M., J. L. Lean, and N. R. Sheeley Jr. (2005), Modeling the Sun's magnetic field and irradiance since 1713, Astrophys. J., 625, 522-538, doi:10.1086/429689.

Wolf, R. (1884), Astronomische mitteilungen LXI, Astron. Mitt. Eidenossischen Sternwarte Zurich, 7, 1-40.

E. W. Cliver, Space Vehicles Directorate, Air Force Research Laboratory, Hanscom AFB, MA 01731-3010, USA.

L. Svalgaard, HEPL, Stanford University, Cedar Hall, Via Ortega, Stanford, CA 94305-4085, USA. (leif@leif.org) 